\title{
Walory krajobrazowe lasów podmiejskich Rzeszowa w aspekcie tworzenia przestrzeni wypoczynkowej
}

\author{
Tomasz Dudek \\ e-mail: tdudek80@ur.edu.pl \\ Katedra Agroekologii, Wydział Biologiczno-Rolniczy, Uniwersytet Rzeszowski \\ Department of Agroecology, Faculty of Biology and Agriculture, University of Rzeszów
}

\begin{abstract}
Streszczenie: Celem pracy jest ocena walorów krajobrazowych lasów podmiejskich Rzeszowa dla celów rekreacyjnego użytkowania. Waloryzacji krajobrazu leśnego dokonano z perspektywy wnętrz drzewostanowych. W zastosowanej metodzie ocenie poddaje się następujące cechy drzewostanów: wiek, wilgotność siedliska, nachylenie terenu, bonitacja, skład gatunkowy warstwy drzew, budowa piętrowa drzewostanu, pokrycie gleby, barwa, mozaikowatość utożsamiana głównie z formą zmieszania gatunków oraz stopniem zadrzewienia. W pracy dokonano waloryzacji krajobrazu lasów podmiejskich Rzeszowa dla potrzeb rekreacji, położonych w odległości do 10 km od granic administracyjnych miasta i będących w zarządzie Państwowego Gospodarstwa Leśnego Lasy Państwowe. Łącznie dokonano oceny 379 oddziałów leśnych o sumarycznej powierzchni 9261 ha administrowanych przez 4 nadleśnictwa: Strzyżów, Kańczuga, Głogów i Leżajsk. Otrzymane wyniki wskazują, że lasy podmiejskie Rzeszowa posiadają duże (57\%) bądź średnie (41\%) walory krajobrazowe. Większość lasów cechujących się najwyższymi walorami krajobrazowymi możemy znaleźć na południe od Rzeszowa w terenie o urozmaiconej rzeźbie co dodatkowo podnosi walory krajobrazowe jak również zachęca do aktywnego wypoczynku. Duży udział drzewostanów starszych klas wieku, bogaty skład gatunkowy, zielna pokrywa runa, dobra przejrzystość wnętrza lasu, to cechy drzewostanów zachęcające do odwiedzin i kontemplacji z przyrodą we wnętrzach krajobrazu leśnego. Dodatkowo cechy te wpływają korzystnie na przydatność drzewostanów do popularnych form rekreacyjnego użytkowania lasu, takich jak: spacery, nordic walking, bieganie.
\end{abstract}

Słowa kluczowe: krajobraz leśny, rekreacja leśna, czas wolny, lasy podmiejskie

\section{Wstęp}

Rzeszów jest jednym z nielicznych dużych miast w Polsce w których rośnie liczba mieszkańców (1946 r. - 29 tys., 1980 r. -121 tys., 2010 r. - 178 tys., 2015 - 186 tys.). Miasto pochłania okoliczne wioski, w których w miejscu niedawnej uprawy ziemi powstają nowe zabudowania domów jednorodzinnych i w zabudowie szeregowej. Tym samym oddala się od centrum miasta przestrzeń charakteryzująca się krajobrazem wiejskim, krajobrazem pól i łąk ale jednocześnie przybliża się do granic administracyjnych miasta krajobraz leśny. Taki obraz jest wynikiem obowiązujących przepisów prawnych. W Polsce znacznie łatwiej zamienić grunty rolne na cele nie rolnicze niż grunty leśne. W przypadku gruntów leśnych stanowiących własność Skarbu Państwa (81\% w Polsce) taka zmiana użytkowania wymaga zgody ministra właściwego do spraw środowiska.

W miastach, w których rośnie liczba mieszkańców, wzrasta zapotrzebowanie na miejsca wypoczynku i rekreacji. Potrzeby wypoczynkowe miejskiej ludności realizują się najpełniej w krajobrazie naturalnym [Bell $i$ in. 2004], leśnym [Ważyński 1997]. Współcześnie istnieje duże zainteresowanie wypoczynkiem w lasach zwłaszcza wśród ludności miast [Paschalis-Jakubowicz 2009, Destan i Bekiroglu 2011, Dudek 2016b], na co wskazywały wcześniejsze prognozy [Bell i in. 2009]. Mieszkańcy dużych miast chętniej wybierają do wypoczynku lasy zagospodarowane rekreacyjnie [Dudek 2016a]. Rosnące zainteresowanie rekreacją leśną tłumaczy się potrzebą kontaktu człowieka z przyrodą. Udowodniono korzystny wpływ przebywania w lesie zarówno na umysł jak i ciało 
człowieka [Park i in. 2009]. Można zauważyć zależność pomiędzy walorami krajobrazowymi a przydatnością obszarów do celów wypoczynkowych [Kryszak i Kryszak 2010, Meyer 2008]. Jednak nie zawsze duże walory krajobrazowe danego obszaru przekładają się na wykorzystanie jego potencjału rekreacyjnego [Dudek 2014].

Celem pracy jest ocena walorów krajobrazowych lasów podmiejskich Rzeszowa dla celów rekreacyjnego użytkowania.

\section{Materiał i metody}

Obszar województwa podkarpackiego cechuje się jedną z najwyższych lesistości w kraju. Lasy porastają tutaj blisko 680 tys. ha co stanowi 38\% powierzchni, z czego ok. 17\% stanowią lasy prywatnej własności, a pozostałe 83\% lasy publiczne. W pracy dokonano waloryzacji krajobrazu lasów podmiejskich Rzeszowa dla potrzeb rekreacji, położonych w odległości do 10 km od granic administracyjnych miasta i będących w zarządzie Państwowego Gospodarstwa Leśnego Lasy Państwowe. Łącznie dokonano oceny 379 oddziałów leśnych o sumarycznej powierzchni 9261 ha administrowanych przez 4 nadleśnictwa: Strzyżów, Kańczuga, Głogów i Leżajsk. W większości drzewostany te należą do starszych klas wieku liczonych co 20 lat (IV klasa stanowi 42\%, zaś V i starsze, tj. drzewostany w wieku powyżej 80 lat - 37\%). Oceniane lasy rosną na siedliskach świeżych (71\%) oraz wilgotnych (28\%). Las porastający bagna i siedliska mokre zajmuje $1 \%$ powierzchni. Na badanym terenie brak jest natomiast siedlisk suchych. Blisko połowa ocenianych lasów porasta teren równinny (głównie lasy w nadleśnictwach Leżajsk i Głogów), 25\% porasta stok pochyły który jest najbardziej atrakcyjny z punktu widzenia popularnych form rekreacji leśnej [Dudek 2013]. Natomiast $21 \%$ drzewostanów porasta stok spadzisty lub stromy (nachylenie $13-30^{\circ}$ ), a pozostałe $4 \%$ stok łagodny. Zdecydowana większość lasów cechuje się budową jednopiętrową (98\%). Drzewostany o budowie 2-piętrowej porastają jedynie 213 ha (2\% wszystkich), natomiast wielopiętrowych drzewostanów nie odnotowano. Lasy podmiejskie Rzeszowa cechuje wysoki stopień zróżnicowania składu gatunkowego dendroflory. Drzewostany wielogatunkowe stanowią 10\%, drzewostany mieszane 3-5 gatunków panujących - 33\%, mieszane z dwoma gatunkami panującymi i do 5 gatunków drzew i krzewów - 10\%, lite lub mieszane z 2 gat. i 6-10 gatunków drzew i krzewów - 39\%. Drzewostany lite stanowią $8 \%$ ocenianych lasów podmiejskich Rzeszowa.

Waloryzacji krajobrazu leśnego dokonano z perspektywy wnętrz drzewostanowych metodą opublikowaną na łamach czasopisma Przestrzeń i Forma [Dudek 2016c - w druku]. W metodzie tej ocenie poddaje się następujące cechy drzewostanów: wiek, wilgotność siedliska, nachylenie terenu, bonitacja, skład gatunkowy warstwy drzew, budowa piętrowa drzewostanu, pokrycie gleby, barwa, mozaikowatość utożsamiana głównie z formą zmieszania gatunków oraz stopniem zadrzewienia.

\section{Wyniki}

Otrzymane wyniki wskazują, że lasy podmiejskie Rzeszowa posiadają duże (57\%) bądź średnie (41\%) walory krajobrazowe. Drzewostany o bardzo dużych walorach krajobrazowych porastają 73 ha $(0,8 \%)$, zaś o małych walorach 26 ha, co stanowi zaledwie 0,3\% wszystkich (tab. 1). Natomiast nie odnotowano drzewostanów o bardzo małych walorach krajobrazowych. Fakt ten można tłumaczyć niskim udział najmłodszych drzewostanów ( | klasa wieku - 2\%, || - 6\%) oraz siedlisk bagiennych i mokrych (1\%). Korzystny był również wskaźnik bonitacji. Drzewostany w najwyższej klasie bonitacji (I klasa) zajmują 66\%, w II klasie - 30\%, a w III - 4\%. Brak natomiast drzewostanów w dwóch najniższych klasach bonitacji (IV i V).

Największy wpływ na przynależność danego drzewostanu do klasy estetyczności krajobrazu miały następujące cechy drzewostanu, w kolejności malejąco: pokrycie runa, nachylenie terenu, skład gatunkowy warstwy drzew i krzewów, wiek drzewostanu. Natomiast najmniejszy (najniższa wartość odchylenia standardowego) budowa piętrowa i bonitacja (tab. 2). 
Tabela 1. Klasy estetyczności krajobrazu leśnego obiektu badań

Forest landscape aesthetic classes for the object of research

\begin{tabular}{|c|c|c|c|c|}
\hline $\begin{array}{c}\text { klasa estetyczności krajobrazu } \\
\text { landscape aesthetic class }\end{array}$ & $\begin{array}{l}\text { suma } \\
\text { punktów } \\
\text { total number } \\
\text { of points }\end{array}$ & $\begin{array}{l}\text { liczba oddziałów } \\
\text { leśnych } \\
\text { number of separate } \\
\text { tree stands }\end{array}$ & $\begin{array}{c}\text { powierzchnia } \\
\text { surface areas } \\
\text { [ha] }\end{array}$ & $\begin{array}{c}\text { udział } \\
\text { share } \\
\text { [\%] }\end{array}$ \\
\hline $\begin{array}{l}\text { I bardzo duże walory } \\
\text { krajobrazowe }\end{array}$ & $39-44$ & 4 & 72,98 & 0,79 \\
\hline $\begin{array}{c}\text { II duże walory krajobrazowe } \\
\text { II high landscape value }\end{array}$ & $31-38$ & 205 & 5317,88 & 57,42 \\
\hline $\begin{array}{l}\text { III średnie walory } \\
\text { krajobrazowe } \\
\text { III average landscape value }\end{array}$ & $22-30$ & 168 & 3843,82 & 41,50 \\
\hline $\begin{array}{l}\text { IV małe walory krajobrazowe } \\
\text { IV low landscape value }\end{array}$ & $13-21$ & 2 & 26,43 & 0,29 \\
\hline $\begin{array}{l}\text { V bardzo małe walory } \\
\text { krajobrazowe }\end{array}$ & do 12 & 0 & 0 & 0,00 \\
\hline
\end{tabular}

Tabela 2. Statystyki podstawowe dla badanych cech drzewostanów Basic statistics for the tree stands covered by the study

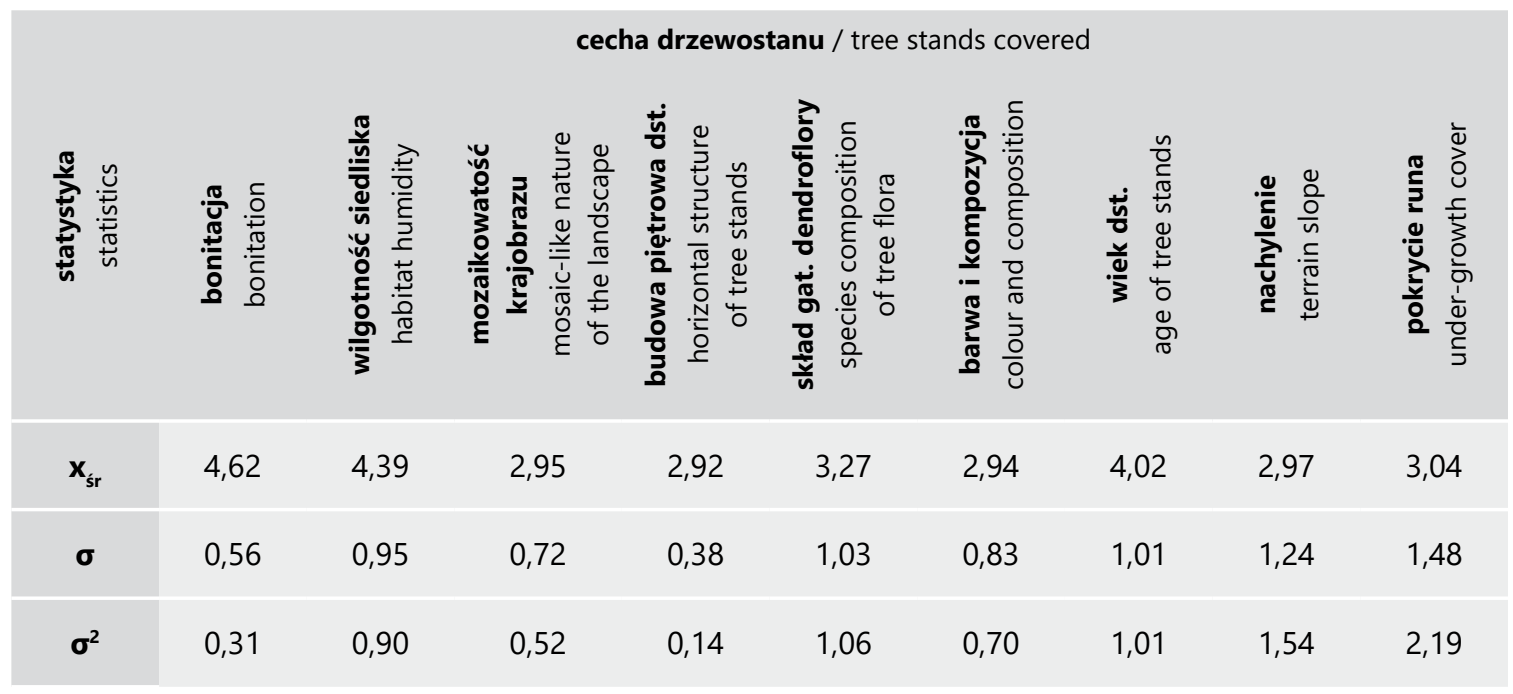

\section{Dyskusja}

Ocenę walorów krajobrazowych okolic Rzeszowa autor przeprowadził już wcześniej, wskazując obszary o najwyższych walorach krajobrazowych: na południowy-wschód od Rzeszowa, pomiędzy Tyczynem a Malawą oraz na południe od linii Siedliska - Tyczyn i na północny-zachód od miejscowości Rudna Mała [Dudek 2012]. Analizując otrzymane wyniki możemy stwierdzić, że również większość lasów cechujących się najwyższymi walorami krajobrazowymi możemy znaleźć na południe od Rzeszowa. Lasy te administrowane są głównie przez Nadleśnictwo Strzyżów, a w znacznie mniejszym udziale przez Nadleśnictwo Kańczuga. 
Wpływ na wartość krajobrazów naturalnych ma przede wszystkim wskaźnik bioróżnorodności [Dymitryszyn i Schwerk 2009] co wykazano również w niniejszej pracy: 3 z 4 cech które miały największy wpływ na przynależność danego drzewostanu do klasy estetyczności krajobrazu (patrz wyniki) wpływają bezpośrednio na wartość tego wskaźnika. Można powiedzieć, że czym wyższy jest ten wskaźnik tym dany krajobraz jest bardziej atrakcyjny, a jego struktura bardziej zróżnicowana. Podobnie Janeczko i in. [2011] poprawę atrakcyjności krajobrazu leśnego widzą głównie w różnicowaniu struktury gatunkowej, wiekowej, warstwowej i przestrzennej drzewostanów. Natomiast zdaniem Kędziory i Karga [2010], mozaikowatość struktury krajobrazu jest czynnikiem determinującym wskaźnik bioróżnorodności. Zgodnie z tą ideą w krajobrazie leśnym niewskazane są drzewostany jednogatunkowe tworzące monokultury na dużych obszarach. Takie drzewostany niewskazane są również z punktu widzenia ochrony i zachowania trwałości lasu w danym krajobrazie. Przyjęta w pracy metoda uwzględnia tą idę; lite jedliny, świerczyny i drzewostany sosnowe otrzymują najniższą wartość biorąc pod uwagę kryterium barwy i kompozycji przyjęte za Korelskim [2000], oraz kryterium składu gatunkowego warstwy drzew i krzewów. Szwedzka agencja ochrony środowiska wskazuje, że dla przetrwania wielu gatunków ptaków i ssaków konieczny jest w lasach udział starodrzewu na poziomie 10-30\% [https://chemlinks.beloit.edu/Rain/ copy/env-qual-crit-forest_landscape.pdf]. Agencja zwraca więc uwagę podobnie jak autor niniejszej pracy, że wiek drzewostanów jest ważnym czynnikiem decydującym o bioróżnorodności ekosystemu leśnego i tym samym o wartości krajobrazu. Również O'Leary i in. [1998] wskazali na obecność dojrzałych drzewostanów w lasach wyróżniających się pod względem atrakcyjności krajobrazu.

W pracy wykazano, że 58\% drzewostanów leżących wokół Rzeszowa, w odległości do $10 \mathrm{~km}$ od granic administracyjnych miasta, ma duże bądź bardzo duże walory krajobrazowe, przy czym większość najcenniejszych krajobrazowo lasów leży na południe od Rzeszowa. Autor przeprowadził badania tą samą metodą w znajdującym się na południowy wschód od Rzeszowa (ok. 25-45 km) Czarnorzecko-Strzyżowskim Parku Krajobrazowym gdzie otrzymał, że ponad 81\% drzewostanów cechuje się dużymi lub bardzo dużym walorami krajobrazowymi [Dudek 2016c - w druku]. Otrzymane wyniki z obu badań wyraźnie wskazują kierunek w którym powinien podążać ruch rekreacyjny mieszkańców Rzeszowa w poszukiwaniu lasów o najwyższych walorach krajobrazowych. W obu pracach autora wskazano te same cechy drzewostanu wpływające w najwyższym stopniu na wartość estetyczną krajobrazu leśnego (patrz wyniki).

Należy zaznaczyć, że w pracy podobnie jak w badaniach Brown [1987] wyżej oceniane były wnętrza krajobrazowe drzewostanów z pokrywą zielną niż pozbawione roślinności - goła ściółka. Natomiast podobnie jak w pracy Brusha [1979] gęsty podrost i podszyt (w pracy przyjęto $\geq 40 \%$ pokrycia terenu) obniżają wartość krajobrazową drzewostanów. Również Scrinzi i Floris [2000] stwierdzają, że najbardziej atrakcyjne są lasy z dobrą widocznością wnętrz, a więc pozbawione bujnie rozwiniętego dolnego piętra oraz warstwy podrostu i podszytu.

\section{Podsumowanie}

Znaczna część lasów podmiejskich Rzeszowa cechuje się dużymi walorami krajobrazowymi (58\%) tworząc atrakcyjną przestrzeń do wypoczynku. Większość tych drzewostanów położonych jest na południe od Rzeszowa w terenie o urozmaiconej rzeźbie co dodatkowo podnosi walory krajobrazowe jak również zachęca do aktywnego wypoczynku. Duży udział drzewostanów starszych klas wieku, bogaty skład gatunkowy, zielna pokrywa runa, dobra przejrzystość wnętrza lasu, to cechy drzewostanów wpływające korzystnie na ocenę krajobrazu leśnego, zachęcające do odwiedzin i kontemplacji z przyrodą. Dodatkowo cechy te wpływają korzystnie na przydatność drzewostanów do innych popularnych form rekreacyjnego użytkowania lasu, takich jak: spacery, nordic walking, bieganie.

Architekci krajobrazu przy wykonywaniu projektów rekreacyjnego zagospodarowania lasów muszą pamiętać, że wszelkie zmiany wprowadzane przez człowieka podczas takich prac powinny w pierwszej kolejności uwzględniać dobro przyrody a dopiero w dalszej użyteczność realizowanego projektu dla społeczeństwa. Zagrożeniem dla krajobrazów leśnych mogą być wprowadzane bezmyślnie obce gatunki z których część jest inwazyjnych zaś inne mogą takimi stać się wraz z obserwowanymi zmianami klimatycznymi. Zwracają na ten problem uwagę również Borgmann i Rodewald [2005]. Autorzy ostrzegają, że przywrócenie krajobrazu leśnego pozbawionego gatunków egzotycznych może okazać się bardzo pracochłonne i kosztowne. 
Działalność gospodarcza człowieka w lesie wymaga niezwykle bogatej wiedzy przyrodniczej a jej ocena możliwa jest często dopiero po latach. Błędy popełnione w przeszłości przy doborze składu gatunkowego drzewostanów (wprowadzono na dużych obszarach świerka pochodzącego głównie z południa Europy) w Karkonoszach i Górach Izerskich doprowadziły w latach 80-tych ubiegłego wieku do całkowitego rozpadu litych drzewostanów świerkowych zmieniając zupełnie tamtejszy krajobraz. Podobne zagrożenie trwałości lasów w krajobrazie górskim współcześnie dotyczy drzewostanów świerkowych w Beskidzie Śląskim i Żywieckim, gdzie na obszarze kilkuset hektarów las przestał już istnieć. Odbudowa ekosystemu leśnego w górskim krajobrazie jest procesem złożonym i długotrwałym. Dlatego zanim podejmiemy jakieś decyzje pod wpływem współczesnych potrzeb, należy przeanalizować możliwe negatywne skutki projektowanych rozwiązań w przyszłości.

\section{Piśmiennictwo}

[1] Bell P.A., Greene Th.C., Fisher J.D., Baum A., 2004. Psychologia środowiskowa. Gdańskie Wydawnictwo Psychologiczne, Gdańsk.

[2] Bell S., Simpson M., Tyrväinen L., Sievänen T., Pröbstl U., 2009. European Forest Recreation and Tourism: A Handbook. Taylor \& Francis, London.

[3] Borgmann K.L., Rodewald A.D., 2005. Forest Restoration in Urbanizing Landscapes: Interactions Between Land Uses and Exotic Shrubs. Restoration Ecology 13(2), 334-340.

[4] Brown T.C., 1987. Production and cost of scenic beauty: examples for a ponderosa pine forest. Forest Science 33(2), 394-410.

[5] Brush R.O., 1979. The attractiveness of woodlands: Perceptions of forest landowners in Massachusetts. Forest Science 25(3), 495-506.

[6] Destan S., Bekiroğlu S., 2011. Evaluation of the territorial system of forest recreation by natural indicators: Belgrade forest example. African Journal of Agricultural Research 6(1), 212-223.

[7] Dudek T., 2012. Ocena walorów krajobrazowych okolic Rzeszowa. Acta Sci. Pol., Administratio Locorum 11(1), 53-59.

[8] Dudek T., 2013. Ocena potencjału rekreacyjnego lasów w terenie o zróżnicowanej orografii na przykładzie Czarnorzecko-Strzyżowskiego Parku Krajobrazowego. Sylwan 157(10), 775-779.

[9] Dudek T., 2014. Potencjał rekreacyjny Magurskiego Parku Narodowego a rzeczywista liczba zwiedzających. Sylwan 158(11), 875-879.

[10] Dudek T., 2016a. Needs of the local population related to development of forests for recreational purposes: example of south-eastern Poland. Journal of Forest Science 62(1), 35-40.

[11] Dudek T., 2016b. Potencjał rekreacyjny lasów podmiejskich Rzeszowa wobec zapotrzebowania na wypoczynek w lasach wśród mieszkańców województwa podkarpackiego. Sylwan 160(2), 169-176.

[12] Dudek T., 2016c. Waloryzacja krajobrazu leśnego Czarnorzecko-Strzyżowskiego Parku Krajobrazowego. Przestrzeń i Forma 26, 187-200.

[13] Dymitryszyn I., Szchwerk A., 2009. Piękno scenerii krajobrazu - turystyka a różnorodność gatunkowa biegaczowatych - przykład badań z Puszczy Piskiej i Drawieńskiego Parku Narodowego. Studia i Materiały Centrum Edukacji Przyrodniczo-Leśnej 4(23), 100-109.

[14] Janeczko E., Woźnicka M., Mandziuk A., 2011. Potrzeby i preferencje społeczne w aspekcie kształtowania krajobrazu leśnego. Studia i Materiały Centrum Edukacji Przyrodniczo-Leśnej 3(28), 117-121.

[15] Kędziora A., Karg J., 2010. Zagrożenia i ochrona różnorodności biologicznej. Nauka 4, 107-114.

[16] Koreleski K., 2000. Pozaprodukcyjne funkcje terenów leśnych i ich szacowanie. Wyd. Akademii Rolniczej w Krakowie.

[17] Kryszak A., Kryszak J., 2010. Walory przyrodniczo-krajobrazowe i kulturowe doliny rzeki Główna. Acta Sci. Pol., Administratio Locorum 9(3), 63-69.

[18] Meyer B., 2008. Krajobraz jako element atrakcyjności turystycznej obszaru. Studia krajobrazowe jako podstawa właściwego gospodarowania przestrzenią. Praca zbiorowa pod red. A. Zaręby, D. Chylińskiej. Wyd. Wrocławskiego Towarzystwa Naukowego, 119-126.

[19] O'Leary T.N., McCormack A.G., Clinch J.P., 1998. Tourists perceptions of forestry in the Irish landscape - an initial study. Forest \& Landscape Research 1(5), 473-490.

[20] Park B.J., Tsunetsugu Y., Kasetani T., Morikawa T., Kagawa T., Miyazaki Y., 2009. Physiological effects of forest recreation in a young conifer forest in Hinokage Town, Japan. Silva Fennica 43(2), 291-301. 
[21] Paschalis-Jakubowicz P., 2009. Leśnictwo a leśna turystyka i rekreacja. Studia i Materiały Centrum Edukacji Przyrodniczo-Leśnej 4(23), 29-35.

[22] Scrinzi G., Floris A., 2000. Featuring and modeling forest recreation in Italy. Forestry 73(2), 173-185.

[23] Ważyński B., 1997. Urządzanie i zagospodarowanie lasu dla potrzeb turystyki i rekreacji. Wyd. Akademii Rolniczej, Poznań.

[24] https://chemlinks.beloit.edu/Rain/copy/env-qual-crit-forest_landscape.pdf; dostęp 05.10.2015

\title{
Scenic qualities of suburban forests of Rzeszów from the viewpoint of designing areas for leisure
}

\begin{abstract}
The study focuses on assessing scenic qualities of the suburban forests of Rzeszów for the needs of use for recreation. Valorisation of the forest landscape has been performed from the perspective of inner tree stands. The applied method involves assessment of such features of tree stands as: age, moisture of habitat, terrain inclination, quality classification, species composition of the tree layer, floor structure of the stands, soil cover, colour, heterogeneity, identified mainly as the type of mixture of species and level of stand density. The study was designed to valorise the landscape of suburban forests of Rzeszów, for the needs of recreation, located at a distance up to $10 \mathrm{~km}$ from the administrative borders of the city, and administered by the "State Forests" National Forest Holding. The assessment was performed for the total of 379 forest units, jointly comprising an area of 9261 ha, and administered by four forest districts: Strzyżów, Kańczuga, Głogów and Leżajsk. The suburban forests of Rzeszów are found with high (57\%) or moderate (41\%) scenic qualities. Majority of the forests with the highest scenic qualities are located south of Rzeszów, in areas with varied terrain, which additionally enhances these scenic qualities and encourages for active leisure. Large proportion of stands representing older age classes, diverse species composition, herbaceous ground cover, and good visibility inside the forest, these are qualities which attract visitors and inspire them to contemplate the nature within the forest landscapes. Additionally, these features contribute to the usefulness of the forests for popular recreation activities, such as: hiking, Nordic walking, running.
\end{abstract}

Key words: forest landscape, forest recreation, leisure time, suburban forests 